\title{
Diastereoselective cyclopropanation by using Camphorpyrazolidinone derived $\alpha, \beta$-Unsaturated Amides and Ylide
}

\author{
Gondi Sudershan Reddy, ${ }^{1 *}$ \\ ${ }^{1}$ Departments of Chemistry, National Taiwan Normal University, Taipei, Taiwan, 116 (ROC). \\ *Correspondence email: gondisr@gmail.com
}

\begin{abstract}
High to moderate diastereoselectivity and high chemical yield are observed in the Michael addition of ylide and chiral camphorpyrazolidinone ylide to an optically pure $\alpha, \beta$-unsaturated carboxylic acid derivatives derived from a chiral camphorpyrazolidinone and $\alpha, \beta$-unsaturated carbonyl respectively. A novel route to the asymmetric synthesis of cyclopropanation derivatives is described.
\end{abstract}

Key words: diastereoselectivity, camphorpyrazolidinone, Michael addition, cyclopropanation, ethyl (dimethylsulfuranylidene) acetate, Chiral Sulfur Ylide and optically pure.

Introduction: Much attention has been given in recent years to the preparation of enantiopure cyclopropyl compounds because such compounds occur widely in natural products $^{1,2}$ and synthetic pharmaceuticals and their enantiomers often exhibit different biological activities ${ }^{3,4}$. So, the efficient stereoselective synthesis of chiral nonracemic cyclopropanes continues to be one of the important tasks in organic synthesis. A variety of efficient synthetic methods were reported, of which Simons-Smith reaction and metalcatalysed $^{5-7}$ decomposition of diazo compound in the presence of alkenes have been known for years. Based on previous studies of Cohen ${ }^{8,9}$ and Julia ${ }^{10}$ proposed that Sulfur ylides $^{11,12}$ as a substitute for the potentially explosive, toxic, and carcinogenic diazo compounds ${ }^{13}$ in cyclopropanation. 
It is well known, that sulfur ylides ${ }^{14}$ react with carbonyl groups or with electron deficient carbon-carbon double bond in a two-step reaction to afford epoxide or cyclopropanes, respectively. ${ }^{15}$ Sulfur ylide in situ generated by treatment of ethyl dimethyl sulfonium acetate bromide with DBU, were reacted with ab cyclic enones, ${ }^{16,17}$ chiral enones ${ }^{18}$ and with $\mathrm{N}$-enoyl oxazolidinones in presence of Lewis acids ${ }^{19}$ are reported in the literature. However, the use of chiral auxiliary $\alpha-\beta$ unsaturated ester or amide with stabilised sulfur ylide is limited. So far few methods has been reported, such as using pyroglutamic acid $(\mathrm{O}, \mathrm{N}$-acetal and $\mathrm{N}$-Boc-pyrrolinone) as a chiral auxiliary $\alpha-\beta$ unsaturated amide with stabilized sulfur ylide. ${ }^{12,20}$ However the Diastereoselectivity is very poor. Still there are demands for better Diastereoselectivity methods. Therefore, development of new methods for stereoselective cyclopropanation of the $\alpha-\beta$ unsaturated ester or amide which bear an appropriate chiral auxiliary continues to be an important area of research.

\section{Present Work:}

Part-A: Cyclopropanation from Chiral $\alpha, \beta$-unsaturated carbonyls with simple ylides:

We have found recently that $\alpha, \beta$-unsaturated carbonyl camphor pyrazolidinone, an efficient chiral auxiliary that allows its use for Aziridination ${ }^{21}$ and Epoxidation ${ }^{22}$. Now we describe here an approach to asymmetric cyclopropanation involving the use of optically pure $\alpha, \beta$-unsaturated carboxylic acid derivatives derived from a chiral camphorpyrazolidinone as a Michael accepter of ethyl (dimethylsulfuranylidene) acetate. The mechanism undoubtedly was a nucleophilic attack by ylide carbon (step-1) followed by ring closure with elimination of dimethyl sulfide (step-2). The cyclopropanation reaction is not stereoselective, either diastereomer ${ }^{23}$ may be obtained from the diastereomeric mixture. The outcome of stereoselectivity totally depends on chiral substrate and solvent 
polarity. The carboethoxy methylene transfer to the $\alpha, \beta$-unsaturated double bond is reminiscent of the methylene transfer with Dimethyl oxo-sulfonium methylide ${ }^{24}$.

The cyclopropanation of olefin and with ethyl (dimethylsulfuranylidene) acetate has been studied as a model for this reaction. We screened different solvents (see Fig. S1) and found that the toluene at higher temperature and acetonitrile at room temperature are ideal one.

Scheme-1, Cyclopronation with Sulfur Ylide
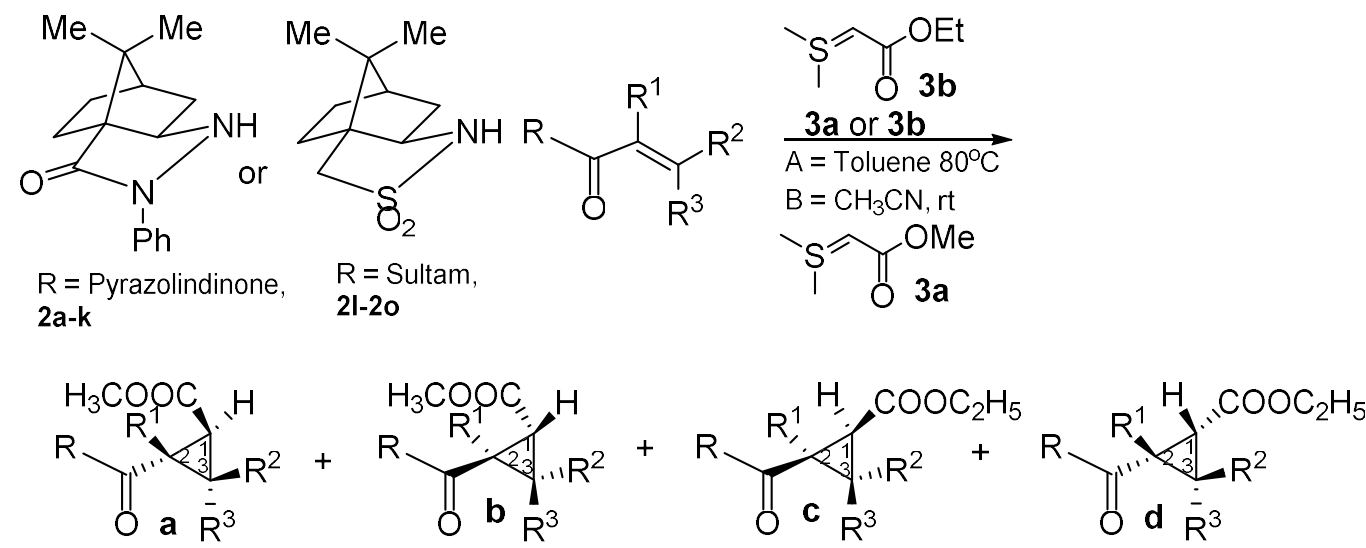
$1 S, 2 S$
$1 \mathrm{R}, 2 \mathrm{R}$
$1 S, 2 R$
$1 \mathrm{R}, 2 \mathrm{~S}$

\begin{tabular}{ccccccccccc|}
\hline entry & Substrate & $\mathbf{R}_{\mathbf{1}}$ & $\mathbf{R}_{\mathbf{2}}$ & $\mathbf{R}_{\mathbf{3}}$ & Method & Time $(\mathbf{h})$ & Yield & d.ratio* & Major & Minor \\
\hline 1 & $2 \mathrm{a}$ & $\mathrm{H}$ & $\mathrm{H}$ & $\mathrm{H}$ & $\mathrm{A}$ & 24 & 90 & $3: 1$ & $4 \mathrm{a}$ & $4 \mathrm{~b}$ \\
2 & $2 \mathrm{a}$ & $\mathrm{H}$ & $\mathrm{H}$ & $\mathrm{H}$ & $\mathrm{A}$ & 24 & 94 & $3: 1$ & $5 \mathrm{a}$ & $5 \mathrm{~b}$ \\
3 & $2 \mathrm{a}$ & $\mathrm{H}$ & $\mathrm{H}$ & $\mathrm{H}$ & $\mathrm{B}$ & 24 & 92 & $2: 1$ & $5 \mathrm{a}$ & $5 \mathrm{~b}$ \\
4 & $2 \mathrm{l}$ & $\mathrm{H}$ & $\mathrm{H}$ & $\mathrm{H}$ & $\mathrm{A}$ & 24 & 40 & $>99.5$ & $6 \mathrm{a}$ & 0 \\
5 & $2 \mathrm{l}$ & $\mathrm{H}$ & $\mathrm{H}$ & $\mathrm{H}$ & $\mathrm{B}$ & 24 & 30 & $>99.5$ & $6 \mathrm{a}$ & 0 \\
6 & $2 \mathrm{~b}$ & $\mathrm{H}$ & $\mathrm{Ph}$ & $\mathrm{H}$ & $\mathrm{A}$ & 24 & 43 & $>99.5$ & $7 \mathrm{~b}$ & 0 \\
7 & $2 \mathrm{~b}$ & $\mathrm{H}$ & $\mathrm{Ph}$ & $\mathrm{H}$ & $\mathrm{B}$ & 24 & 39 & $>99.5$ & $7 \mathrm{c}$ & 0 \\
8 & $2 \mathrm{~m}$ & $\mathrm{H}$ & $\mathrm{Ph}$ & $\mathrm{H}$ & $\mathrm{A}$ & 24 & 25 & $>99.5$ & $8 \mathrm{~b}$ & 0 \\
9 & $2 \mathrm{~m}$ & $\mathrm{H}$ & $\mathrm{Ph}$ & $\mathrm{H}$ & $\mathrm{B}$ & 48 & 23 & $>99.5$ & $8 \mathrm{~b}$ & 0 \\
10 & $2 \mathrm{c}$ & $\mathrm{H}$ & $\mathrm{COOEt}$ & $\mathrm{H}$ & $\mathrm{A}$ & 24 & 93 & $>99.5$ & $9 \mathrm{a}$ & 0 \\
11 & $2 \mathrm{n}$ & $\mathrm{H}$ & $\mathrm{COOEt}$ & $\mathrm{H}$ & $\mathrm{A}$ & 24 & 40 & $>99.5$ & $10 \mathrm{a}$ & 0 \\
12 & $2 \mathrm{~d}$ & $\mathrm{H}$ & $\mathrm{C}_{3} \mathrm{H}_{7-n}$ & $\mathrm{H}$ & $\mathrm{A}$ & 24 & 91 & $>99.5$ & $11 \mathrm{a}$ & 0 \\
13 & $2 \mathrm{~d}$ & $\mathrm{H}$ & $\mathrm{C}_{3} \mathrm{H}_{7-n}$ & $\mathrm{H}$ & $\mathrm{B}$ & 24 & 76 & $>99.5$ & $11 \mathrm{~d}$ & 0 \\
14 & $2 \mathrm{e}$ & $\mathrm{H}$ & $\mathrm{CH}_{3}$ & $\mathrm{H}$ & $\mathrm{A}$ & 24 & 87 & $>99.5$ & $12 \mathrm{a}$ & 0 \\
15 & $2 \mathrm{f}$ & $\mathrm{H}$ & $\mathrm{C}_{3} \mathrm{H}_{7-\text {-iso }}$ & $\mathrm{H}$ & $\mathrm{A}$ & 24 & 80 & $>99.5$ & $13 \mathrm{a}$ & 0 \\
16 & $2 \mathrm{~g}$ & $\mathrm{H}$ & $\mathrm{C}_{4} \mathrm{H}_{9-t e r t}$ & $\mathrm{H}$ & $\mathrm{A}$ & 72 & $\mathrm{NR}$ & 0 & 0 & 0 \\
17 & $2 \mathrm{~h}$ & $\mathrm{H}$ & $\mathrm{CH}_{3}$ & $\mathrm{CH}$ & $\mathrm{A}$ & 72 & $<1$ & 0 & $14 \mathrm{a}$ & 0 \\
18 & $2 \mathrm{i}$ & $\mathrm{CH}_{3}$ & $\mathrm{CH}_{3}$ & $\mathrm{H}$ & $\mathrm{A}$ & 72 & $<1$ & $1: 1$ & 15 & 0 \\
19 & $2 \mathrm{o}$ & $\mathrm{H}$ & $\mathrm{CH}_{3}$ & $\mathrm{CH}_{3}$ & $\mathrm{~A}$ & 72 & $\mathrm{NR}$ & 0 & 0 & 0 \\
20 & $2 \mathrm{j}$ & $\mathrm{CH}_{3}$ & $\mathrm{H}$ & $\mathrm{H}$ & $\mathrm{A}$ & 24 & 87 & $>99.5$ & $16 \mathrm{~b}$ & 0 \\
21 & $2 \mathrm{j}$ & $\mathrm{CH}_{3}$ & $\mathrm{H}$ & $\mathrm{H}$ & $\mathrm{B}$ & 24 & 88 & $3: 1$ & $16 \mathrm{c}$ & $16 \mathrm{~b}$ \\
22 & $2 \mathrm{k}$ & $\mathrm{Br}$ & $\mathrm{H}$ & $\mathrm{H}$ & $\mathrm{A}$ & 24 & 78 & $>99.5$ & $17 \mathrm{~b}$ & 0 \\
23 & $2 \mathrm{k}$ & $\mathrm{Br}^{2}$ & $\mathrm{H}$ & $\mathrm{H}$ & $\mathrm{B}$ & 24 & 65 & $1: 1$ & 18 & 0 \\
\hline
\end{tabular}

d.ratio* $=$ Diastereomers ratio 
The general utility of this procedure was further demonstrated by using several olefin substituents (2a-2o). The simple olefin $\mathbf{2 a}$ with methyl ester ylide $\mathbf{3 a}$ was gives major product $\mathbf{4 a}$ as $1 \mathrm{~S}, 2 \mathrm{~S}$, confirmed by ORTEP and minor product $\mathbf{4 b}$. Repeated the same reaction with ethyl ester ylide (3b) gives as similar diastereomers ratio. This time the minor product $\mathbf{5 b}$ forms crystals, by ORTEP confirmed the product as $1 \mathrm{R}, 2 \mathrm{R}$. Treatment of Nacryoylbornane[10, 2]sultam (2I) under the same reaction conditions resulted in the desired diastereomeric products in a ratio of $1: 1$ with low chemical yield $40 \%$ (in toluene) and $30 \%$ in acetonitrile respectively. After purification, one product $\mathbf{6 a}$ is confirmed as $1 R, 2 R$ by ORTEP. The less reactivity of the camphorsultam toward cyclopropanation may be due to the electrostatic repulsion between the sulfone functionality in the chiral auxiliary with the nucleophilic sulfur ylide ${ }^{25}$. The beta phenyl substrate, $\mathbf{2} \mathbf{b}$ gives exclusive $\mathbf{7 a}$ and $\mathbf{7 b}$ in toluene and acetonitrile, respectively. Newly formed stereogenic centers in $\mathbf{7 b}$ are confirmed by ORTEP as $1 \mathrm{~S}, 2 \mathrm{R}, 3 \mathrm{R}$. where the ethyl ester group is in cis orientation with chiral amide bond. In case of sultam substrate $\mathbf{2 m}$ gives same product $\mathbf{8 b}$ in toluene and acetonitrile in 25 and $23 \%$ yield, respectively. The ORTEP confirmed $\mathbf{8 b}$ absolute configurations as $I R, 2 R, 3 R$, where ethyl ester group is trans to chiral auxiliary amide. Similarly, the beta-ester $\mathbf{2 c}$, gives $\mathbf{9 a}$ in toluene. The 1,2-dicarbonyl groups in $9 \mathbf{a}$ are determined to be cis oriented and the absolute stereochemistry of the cyclopropyl moiety was assigned to be $(1 S, 2 R, 3 S)$. The corresponding sultam ester $\mathbf{2}$ n gives same diastereomeric product $10 \mathbf{a}$ with low chemical yield (40\%). The beta propyl $2 \mathbf{d}$ gives $1 \mathrm{~S}$, 2S, 3S stereogenic centered configurated product 11a, where substituents on cyclopropane ring are trans to each other. The beta tertiary butyl $\mathbf{2} \mathbf{g}$ group does not gives product at all even prolong reaction time. For $\alpha$-methyl $\mathbf{2} \mathbf{j}$ and a-bromo $\mathbf{2 k}$ substituents in toluene we observed high chemical yield $(87 \%$ and $78 \%)$ as well as stereoselectivity $(>99.5 \%)$, whereas in acetonitrile, the chemical yield as well as the selectivity is low. The $\alpha$-methyl substituted cyclopropane ring $16 \mathrm{~b}$ is confirmed as $1 \mathrm{R}, 2 \mathrm{R}$ by OTREP. 
Under this reaction condition, several $\alpha, \beta$-unsaturated carbonyl substrates give moderate to good chemical yield and shows good to excellent in diastereoselectivity. Two solvents were screened for some substrate and found that the chemical yield and diastereoselectivity is higher in toluene for a particular substrate. Interestingly the beta phenyl 2b, altogether gives different product in acetonitrile. For simple olefin substituent, the Diastereoselectivity is decreased from toluene to acetonitrile. In contrast to the reported method for simple cyclopropanation ${ }^{26} \beta$-electron withdrawing group (ester) gives excellent yields in chemical (92\%) as well as diastereoselectivity (>99.5\%). In general, $\alpha$ or $\beta$ substituents olefins give good diastereoselectivity, whereas simple olefin shows poor selectivity. However, despite its utility and simplicity, limitations are sometimes encountered, particularly with less reactive $\beta, \beta$-dimethyl $(\mathbf{2} \mathbf{h})$ and $\alpha, \beta$-dimethyl (2i) substrates, even prolong the reaction time gives only trace number of products $14 a$ and 15 respectively. The sultam $\beta, \beta$-dimethyl (2o) substrates do not give any product at all. It was found that the reaction was greatly dependent upon the molar ratio of sulfur reagent, with lesser equivalents gives less yield, because of self-decomposition of the reagent (at higher temperature in toluene).

Part-B: Cyclopropanation from Chiral ylide with $\alpha-\beta$ unsaturated carbonyl: The simple ylide reaction is feasible in most of the $\alpha-\beta$ unsaturated carbonyl substrate, but need to synthesize chiral derived $\alpha-\beta$ unsaturated carbonyl substrates as well as the different ylides for any changes to be made on cyclopropane ring. There are few reported methods where chiral sulfur ylide ${ }^{27}$ is used for cyclopropanation, but still need a convenient method. Herein we report cyclopropanation formation on reaction of chiral auxiliary having sulfur ylide with $\alpha, \beta$ - unsaturated carbonyls. it is useful particularly where chiral auxiliary with $\alpha-\beta$ unsaturated carbonyl substituted substrates and $\alpha$-substituted yllide synthesis is not possible. 
The cyclopropanation by using chiral ylide $\mathbf{3 d}$ with methacrylate has been studied as a model for this reaction. We screened different solvents and found that the acetonitrile at room temperature is ideal one and gives good chemical yield and diastereoselectivity (Fig. S2).

\section{Scheme-2, Cyclopronation with Chiral Sulfur Ylide}

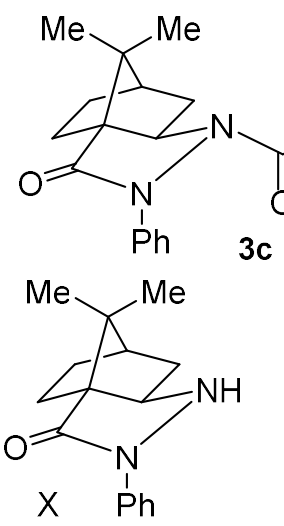<smiles>CS(C)=CC=O</smiles><smiles>[R]C=C([R])C([R])=O</smiles><smiles>[14CH3][14CH3]</smiles>

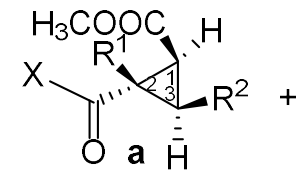

$1 S, 2 S$

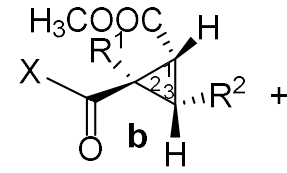

$1 \mathrm{R}, 2 \mathrm{R}$

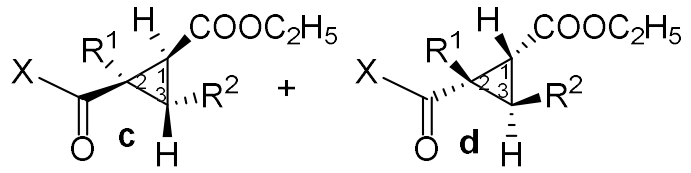

$1 S, 2 R$ $1 \mathrm{R}, 2 \mathrm{~S}$

\begin{tabular}{|c|c|c|c|c|c|c|c|c|c|c|}
\hline Entry & Substrate & $\mathbf{R}$ & $\mathbf{R}_{1}$ & $\mathbf{R}_{\mathbf{2}}$ & Yield & d.ratio* & $\begin{array}{c}\text { Prod- } \\
\text { a }\end{array}$ & $\begin{array}{c}\text { Prod- } \\
\text { b }\end{array}$ & Prod-c & $\begin{array}{c}\text { Prod- } \\
\text { d }\end{array}$ \\
\hline 1 & methacrylate & $\mathrm{OCH}_{3}$ & $\mathrm{H}$ & $\mathrm{H}$ & 85 & 1:11:1:0 & $4 a$ & $4 b$ & $4 \mathrm{c}$ & 0 \\
\hline 2 & ethyl acrylate & $\mathrm{OC}_{2} \mathrm{H}_{5}$ & $\mathrm{H}$ & $\mathrm{H}$ & 91 & $1: 17: 1: 0$ & $5 a$ & $5 b$ & $5 c$ & 0 \\
\hline 3 & oxazolidinone & OXA & $\mathrm{H}$ & $\mathrm{H}$ & 91 & 0:99.5:0:0 & 0 & $19 b$ & 0 & 0 \\
\hline 4 & tiglate & $\mathrm{OCH}_{3}$ & $\mathrm{CH}_{3}$ & $\mathrm{H}$ & 78 & 1:11:4:0 & $20 a$ & $20 \mathrm{~b}$ & $20 c$ & 0 \\
\hline 5 & acrylaldehyde & $\mathrm{CHO}$ & $\mathrm{H}$ & $\mathrm{H}$ & 92 & 1:5:3:0 & $21 a$ & $21 b$ & $21 \mathrm{c}$ & 0 \\
\hline 6 & acrylonitrile & $\mathrm{CN}$ & $\mathrm{H}$ & $\mathrm{H}$ & 83 & $1: 8: 7: 1$ & $22 a$ & $22 b$ & $22 \mathrm{c}$ & $22 d$ \\
\hline 7 & $\begin{array}{l}\text { vinyl methyl } \\
\text { ketone }\end{array}$ & $\mathrm{CH}_{3}$ & $\mathrm{H}$ & $\mathrm{H}$ & 85 & $\operatorname{mix}$ & 23 & 0 & 0 & 0 \\
\hline 8 & fumarate & COOEt & $\mathrm{H}$ & COOEt & 91 & 1:0:23:0 & 0 & $9 b$ & $9 c$ & 0 \\
\hline 9 & maleate & COOEt & $\mathrm{H}$ & COOEt & 93 & $1: 0: 25: 0$ & 0 & $9 \mathrm{~b}$ & $9 c$ & 0 \\
\hline 10 & hexenaldehyde & $\mathrm{CHO}$ & $\mathrm{H}$ & $\mathrm{C}_{3} \mathrm{H}_{7-\mathrm{n}}$ & 87 & 1:0:9:0 & 0 & $24 b$ & 0 & 0 \\
\hline
\end{tabular}

d.ratio $=$ Diastereomers ratio

With methacrylate, ethyl acrylate, major products $4 \mathbf{b}, \mathbf{5 b}(1 \mathrm{R}, 2 \mathrm{R})$ and minor products $\mathbf{4 a}$, 5a $(1 \mathrm{~S}, 2 \mathrm{~S})$ and $\mathbf{4 c}, \mathbf{5 c}(1 \mathrm{~S}, 2 \mathrm{R})$ were isolated. When oxazolidinone were treated, complete diastereoselectivity is observed, as product $19 \mathrm{~b}$ where characterised by ORTEP, as $1 \mathrm{R}, 2 \mathrm{R}$ and isolated in $91 \%$ yield. The methyl tiglate gives three diastereomer isomers, minor product $20 \mathrm{a}$ as $1 \mathrm{~S}, 2 \mathrm{~S}$ and major product $20 \mathrm{~b}$ as $1 \mathrm{R}, 2 \mathrm{R}$ which was characterized by ORTEP, where the methyl ester is trans to chiral amide. The third diastereoisomer 20c where characterized as $1 R, 2 S$ by ORTEP where the methyl ester group is cis to chiral 
amide. The acrylaldehyde also 3 products $21 \mathrm{a}, \mathbf{2 1 b}$ and $21 \mathrm{c}$ after repeated recrystallizations, no crystals were formed, whereas the acrylonitrile gives full spectrum of four possible products $\mathbf{2 2 a}, \mathbf{2 2} \mathbf{b}, \mathbf{2 2 c}$ and $\mathbf{2 2 d}$. The vinyl methyl ketone gives mixture of products 23 which are inseparable. These multiple products formations can be explained that chiral ylide can be attack from either side of simple $\alpha, \beta$-unsaturated carbonyl substrates. As expected, fumarate gives $9 b,(1 S, 2 R)$ as major product, but surprisingly, the maleate also gives same $9 \mathrm{~b}(1 \mathrm{R}, 2 \mathrm{~S})$ as major product. This can be explained the esters groups are in cis orientation is most stable than anti orientation. Surprisingly, the hexenaldehyde is gives more selective product $24 \mathrm{~b}$ with chiral ylide. To improve the selectivity, we generated in situ chiral sulfide from chiral diazo ${ }^{28}$ in presence of $\mathrm{Rh}_{2}(\mathrm{OAc})_{4}$ and diphenyl sulfide ${ }^{29}$, however it is limited to olefin only (Fig.S3). In this method the stereoselectivity is excellent for amides but not esters but other possible diastereomers can be synthesised.

\section{Part-C: Cyclopropanation from Chiral ylide and Chiral $\alpha, \beta$-unsaturated carbonyls:}

After studying the cyclopropanation reaction by using chiral $\alpha, \beta$-unsaturated carbonyls and chiral ylide, we studied the combined reaction of chiral $\alpha, \beta$-unsaturated carbonyls (2a-2I) with chiral ylide 3c. Steric hinderance play major rule than stereoselectivity in this type of reactions. Chiral olefin $\mathbf{2 a}$ on reaction with chiral ylide $\mathbf{3 c}$, in various solvents and found that acetonitrile at room temperature is the best choice and gives good chemical yield and diastereoselectivity (Fig. S4). In the class of reaction only olefin and beta-ester are effective. In olefin, the products $\mathbf{2 5 b}$ stereoselectivity is increases to $93 \%$ in contrast to beta-ester $\mathbf{2 6 b}$, where its stereo selectivity decreases. Surprisingly, the beta-alkyl is ineffective and as expected $\alpha$-substituted or $\alpha \beta$-disubstituted substrate are unreactive due to steric hinderance. 


\section{Scheme-3, Cyclopronation by Chiral substrate with Chiral Sulfur Ylide}
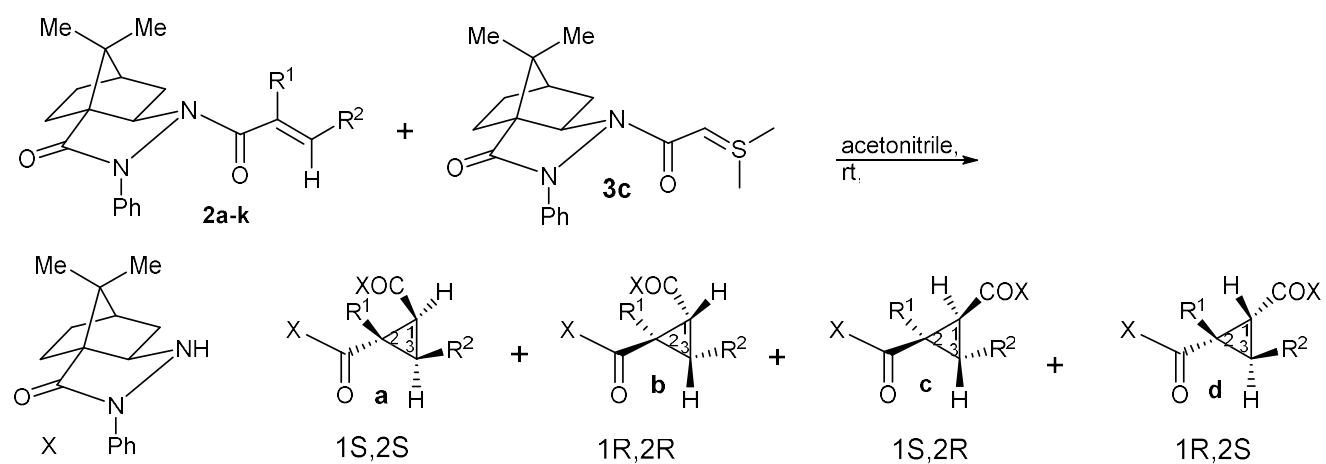

\begin{tabular}{|cccccccccc|}
\hline Entry & Substrate & $\mathbf{R}_{\mathbf{1}}$ & $\mathbf{R}_{\mathbf{2}}$ & Yield & d.ratio* & Prod-a & Prod-b & Prod-c & Prod-c \\
\hline 1 & $2 \mathrm{a}$ & $\mathrm{H}$ & $\mathrm{H}$ & 90 & $1: 27: 0: 0$ & $25 \mathrm{a}$ & $25 \mathrm{~b}$ & 0 & 0 \\
2 & $2 \mathrm{c}$ & $\mathrm{H}$ & $\mathrm{COOEt}$ & 92 & $1: 10: 0: 0$ & $26 \mathrm{a}$ & $26 \mathrm{~b}$ & 0 & 0 \\
3 & $2 \mathrm{e}$ & $\mathrm{CH}_{3}$ & $\mathrm{H}$ & $\mathrm{NR}$ & & & & & \\
4 & $2 \mathrm{k}$ & $\mathrm{H}$ & $\mathrm{CH}_{3}$ & $\mathrm{NR}$ & & & & & \\
5 & $2 \mathrm{i}$ & $\mathrm{CH}_{3}$ & $\mathrm{CH}_{3}$ & $\mathrm{NR}$ & & & & & \\
\hline
\end{tabular}

Mechanism: From this structure it may be inferred that the transition state for this cyclopropanation involved a non-chelate model in which the bond dipole carbonyl group of chiral camphorpyrazolidinone and the attacking carbon are oriented in opposite direction. The 1,3-elimination occurred preferentially from the carbonyl side of chiral camphorpyrazolidinone, leading to the formation of the major diastereoisomer. Diazo acetamide, 3d goes in similar mechanism, except in situ generated ylide (Fig. S5). In most of the cases trans structure was assigned to the major compound with the help of ${ }^{1} \mathrm{H}$ NMR spectroscopy and ORTEP.

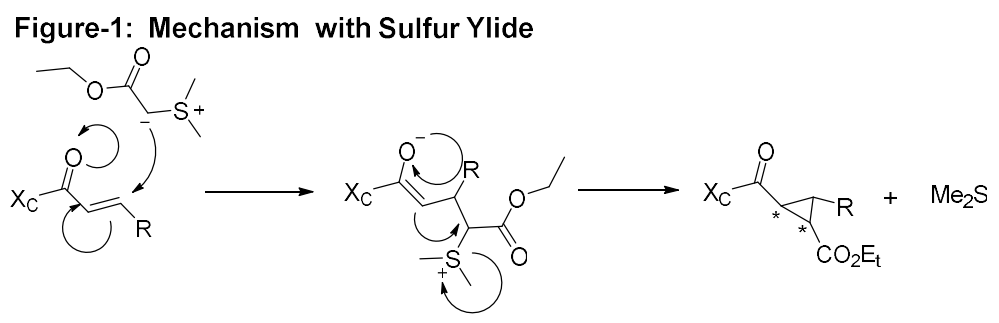

After studying various cyclopropanation approaches, we came to conclusion, that methodA is give better diastereomer products, than chiral ylide (method-B), whereas diazo in presence of sulfide is limited to unsubstituted $\alpha, \beta$-unsaturated carbonyl only. As expected in Method-C, steric hindrance is played major role than stereoselectivity. 
Applications: The olefin major product is $1 \mathrm{~S}, 2 \mathrm{~S}$ is useful for granzyme $\mathrm{B}$ inhibitrs ${ }^{30}$, glutamate release inhibitors ${ }^{31}$, dopamine D3receptor ligands ${ }^{32}$ and channel blockers ${ }^{33}$ the minor product $1 \mathrm{R}, 2 \mathrm{R}$ useful in synthesising the calcium channel blockers ${ }^{34}$. $\beta$-substituted olefins give highly functionalised 1,2,3-trisubstituted cyclopropane derivatives ${ }^{35,36}$, which can be used to synthesize PCCG-4 and PCCG-13, the subtype-selective antagonists for metabotropic glutamate receptor. ${ }^{25}$ renin and retroviral protease ${ }^{37}$. The diesterCyclopropane were used for stereochemical studies ${ }^{38,39,} \alpha$-bromo substitute in particularly important, the obtained cyclopropane derivatives can be further chemically manipulate to give 1-Aminocyclopropane-1-carboxylic acid derivatives (ACC) which constitute a family $\alpha, \alpha$-amino acid of tremendous interest because of their biological activity and potential use in conformationally restricted peptides. ${ }^{40,41,2}$ The 1-methyl1-ester product, $1 \mathrm{~S}, 2 \mathrm{~S}$ is useful for synthesis of neurodegenerative disorders inhibitos ${ }^{42}$. Its major diastereomer product $(1 R, 2 R)$ is useful for the $\beta$-amino acid $^{43}$, aspartic protease activity ${ }^{44}$ Coenzyme B12dependent 2-Methyleneglutarate Mutase $^{45}$, the cis isomer $(1 \mathrm{~S}, 2 \mathrm{R})$ is useful for the polyamines for cancer therapy ${ }^{46}$

Conclusion: we have developed a stereo chemically controlled reaction for synthesizing the enantiopure cyclopropanes by using $\alpha, \beta$-unsaturated carboxylic acid derivatives $2 \mathbf{a}-\mathbf{k}$ derived from a chiral camphorpyrazolidinone as a Michael acceptor of ethyl (dimethylsulfuranylidene) acetate and chiral ylide $3 c$ with $\alpha, \beta$-unsaturated carbonyls. Its efficiency was demonstrated without using any metals. It is obviously that the present method would be useful for synthesizing other important 1,2,3-trisubstituted cyclopropane derivatives.

\section{- Acknowledgement}

G.S.R thankful to National Science Council of Taiwan, (ROC) for financial support in the form of Post-Doctoral Fellowship during February 2000-July 2003. G.S.R is thankful to 
Kwunmin Chen at National Taiwan Normal University, Taipei, Taiwan, for conducting the experiments and collection and processing of the spectral data and X-ray data are gratefully acknowledged.

- Competing interests: There is no Competing Interests pending

Data and materials availability: Crystallographic model data is available through the CCDC under identifier 2040634, (3aS,6R,7aR)-8,8-dimethyl-1-((E)-4-methylpent-2-enoyl)2-phenylhexahydro-3a,6-methanoindazol-3(2H)-one (2f); 2040633, (3aS,6R,7aR)-1-((E)4,4-dimethylpent-2-enoyl)-8,8-dimethyl-2-phenylhexahydro-3a,6-methanoindazol-3(2H)-

one (2g): 2039967, methyl (1S,2S)-2-((3aS,6R,7aR)-8,8-dimethyl-3-oxo-2phenyloctahydro-3a,6-methanoindazole- $\quad$ 1-carbonyl)cyclopropane-1-carboxylate $\quad$ (4a); 2039966, Ethyl(1S,2S)-2-((3aS,6R,7aR)-8,8-dimethyl-3-oxo-2-phenyloctahydro-3a,6methanoindazole-1-carbonyl)cyclopropane-1-carboxylate $\quad(5 b) ; \quad 2040540, \quad$ ethyl (1S,2R,3R)-2-((3aS,6R,7aR)-8,8-dimethyl-3-oxo-2-phenyloctahydro-3a,6-

methanoindazole-1-carbonyl)-3-phenylcyclopropane-1-carboxylate (7c); 2040545, ethyl (1R,2R,3R)-2-((6R,7aR)-8,8-dimethyl-2,2-dioxidohexahydro-3H-3a,6-

methanobenzo[c]isothiazole-1-carbonyl) -3-phenylcyclopropane-1-carboxylate $\quad$ (8b); 2040541, Diethyl (1R,2S,3S)-3-((3aS,6R,7aR)-8,8-dimethyl-3-oxo-2-phenyloctahydro3a,6- methanoindazole-1-carbonyl)cyclopropane-1,2-dicarboxylate (9a); 2040546, ethyl (1S,2S,3S)-2-((6R,7aR)-8,8-dimethyl-3-oxo-2-phenyloctahydro-3a,6- methanoindazole-1carbonyl)-3-propylcyclopropane-1-carboxylate (11a); 2039826, ethyl (1R,2R)-2-((6R,7aR)8,8-dimethyl-3-oxo-2-phenyloctahydro-3a,6-methanoindazole-1-carbonyl)-2methylcyclopropane-1-carboxylate(16b); 2040559, methyl (1S,2R)-2-((3aS,6R,7aR)-8,8dimethyl-3-oxo-2-phenyloctahydro-3a,6-methanoindazole-1-carbonyl)-1methylcyclopropane-1-carboxylate (20c). See Fig. S6 for crystals data details. 


\section{References}

1 Doyle, M. P. \& Protopopova, M. N. New aspects of catalytic asymmetric cyclopropanation. Tetrahedron 54, 7919-7946, doi:https://doi.org/10.1016/S00404020(98)00222-1 (1998).

2 Gnad, F. \& Reiser, O. Synthesis and Applications of $\beta$-Aminocarboxylic Acids Containing a Cyclopropane Ring. Chemical Reviews 103, 1603-1624, doi:10.1021/cr010015v (2003).

3 Burgess, K., Ho, K.-K. \& Moye-Sherman, D. Asymmetric Syntheses of 2,3Methanoamino Acids. Synlett 1994, 575-583, doi:10.1055/s-1994-22933 (1994).

4 Reissig, H.-U. \& Zimmer, R. Donor-Acceptor-Substituted Cyclopropane Derivatives and Their Application in Organic Synthesis. Chemical Reviews 103, 1151-1196, doi:10.1021/cr010016n (2003).

5 Schumacher, R. \& Reissig, H.-U. Stereoselective Cyclopropanation of Chiral Carbohydrate-Derived Enol Ethers. Synlett 1996, 1121-1122, doi:10.1055/s-1996-5664 (1996).

6 Mazet, C., Köhler, V. \& Pfaltz, A. Chiral Boron-Bridged Bisoxazolines: Readily Available Anionic Ligands for Asymmetric Catalysis. Angewandte Chemie International Edition 44, 4888-4891, doi:https://doi.org/10.1002/anie.200501111 (2005).

7 Zhu, C. et al. Design, Preparation, X-ray Crystal Structure, and Reactivity of oAlkoxyphenyliodonium Bis(methoxycarbonyl)methanide, a Highly Soluble Carbene Precursor. Organic Letters 14, 3170-3173, doi:10.1021/ol301268j (2012). Cohen, T., Herman, G., Chapman, T. M. \& Kuhn, D. Laboratory model for the biosynthesis of cyclopropane rings. Copper-catalyzed cyclopropanation of olefins by sulfur ylides. Journal of the American Chemical Society 96, 5627-5628, doi:10.1021/ja00824a082 (1974).

9 Chen, D. Y. K., Pouwer, R. H. \& Richard, J.-A. Recent advances in the total synthesis of cyclopropane-containing natural products. Chemical Society Reviews 41, 46314642, doi:10.1039/C2CS35067J (2012).

10 Cimetière, B. \& Julia, M. Alkene Cyclopropanation with Sulfonium Ylids. Synlett 1991, 271-272, doi:10.1055/s-1991-20705 (1991).

11 Murtiashaw, C. W. No pp. given (John Wiley \& Sons, Ltd.).

12 Murtiashaw, C. W. \& Pyne, S. G. 1-5 (John Wiley \& Sons, Ltd.).

13 Green, S. P. et al. Thermal Stability and Explosive Hazard Assessment of Diazo Compounds and Diazo Transfer Reagents. Organic Process Research \& Development 24, 67-84, doi:10.1021/acs.oprd.9b00422 (2020).

14 Zhang, J.-s., Li, X.-j., Liu, F. \& Pan, X.-h. Synthesis of (1R,2S)-2-(3,4difluorophenyl)cyclopropanamine. Jingxi Huagong 30, 64-68, 71 (2013).

15 in Organic Chemistry: A Series of Monographs Vol. 37 (ed Eric Block) 91-127 (Academic Press, 1978).

16 Moher, E. D. Novel asymmetric synthesis of a bicyclo[3.1.0]hexane derivative by an efficient retro-diels-alder strategy. Tetrahedron Letters 37, 8637-8640, doi:https://doi.org/10.1016/S0040-4039(96)02025-4 (1996).

17 Kim, H. Y., Lurain, A. E., García-García, P., Carroll, P. J. \& Walsh, P. J. Highly Enantioand Diastereoselective Tandem Generation of Cyclopropyl Alcohols with up to Four Contiguous Stereocenters. Journal of the American Chemical Society 127, 1313813139, doi:10.1021/ja0539239 (2005).

18 Ma, D. \& Jiang, Y. Stereocontrolled cyclopropanation of Garner's aldehyde derived enones. Tetrahedron: Asymmetry 11, 3727-3736, doi:https://doi.org/10.1016/S09574166(00)00327-X (2000).

19 Mamai, A. \& Madalengoitia, J. S. Lewis acid mediated diastereoselective and enantioselective cyclopropanation of Michael acceptors with sulfur ylides. 
Tetrahedron Letters 41, 9009-9014, doi:https://doi.org/10.1016/S0040-4039(00)01534-3 (2000).

20 Zhang, R., Mamai, A. \& Madalengoitia, J. S. Cyclopropanation Reactions of Pyroglutamic Acid-Derived Synthons with Akylidene Transfer Reagents. The Journal of Organic Chemistry 64, 547-555, doi:10.1021/jo9816109 (1999).

21 Yang, K.-S. \& Chen, K. Enantioselective Aziridination of Alkenes with NAminophthalimide in the Presence of Lead Tetraacetate-Mediated Chiral Ligand. Organic Letters 4, 1107-1109, doi:10.1021/ol0173073 (2002).

22 Fan, C. L., Reddy, G. S. \& Chen, K. Diastereoselective Epoxidation of Camphor NEnoylpyrazolidinones. Journal of the Chinese Chemical Society 50, 1047-1051, doi:https://doi.org/10.1002/jccs.200300148 (2003).

23 Gawley, R. E. Do the Terms "\% ee" and "\% de" Make Sense as Expressions of Stereoisomer Composition or Stereoselectivity? The Journal of Organic Chemistry 71, 2411-2416, doi:10.1021/jo052554w (2006).

24 Paxton, R. J. \& Taylor, R. J. K. Improved Dimethylsulfoxonium Methylide Cyclopropanation Procedures, Including a Tandem Oxidation Variant. Synlett 2007, 0633-0637, doi:10.1055/s-2007-967966 (2007).

25 Curran, D. P., Kim, B. H., Daugherty, J. \& Heffner, T. A. The preparation of optically active $\delta 2-$ isoxazolines. A model for asymmetric induction in the non lewis acid catalyzed reactions of oppolzer's chiral sultam. Tetrahedron Letters 29, 3555-3558, doi:https://doi.org/10.1016/0040-4039(88)85291-2 (1988).

26 Vallgårda, J., Appelberg, U., Csöregh, I. \& Hacksell, U. Stereoselectivity and generality of the palladium-catalysed cyclopropanation of $\alpha, \beta$-unsaturated carboxylic acids derivatized with Oppolzer's sultam. Journal of the Chemical Society, Perkin Transactions 1, 461-470, doi:10.1039/P19940000461 (1994).

27 Ye, S., Huang, Z.-Z., Xia, C.-A., Tang, Y. \& Dai, L.-X. A Novel Chiral Sulfonium Yilde: Highly Enantioselective Synthesis of Vinylcyclopropanes. Journal of the American Chemical Society 124, 2432-2433, doi:10.1021/ja0172969 (2002).

28 Chen, J.-H., Liu, S.-R. \& Chen, K. An Efficient and Convenient Synthesis of Ethyl 1-(4Methoxyphenyl)-5-phenyl-1H-1,2,3-triazole-4-carboxylate. Chem. - Asian J. 5, 328-333, doi:10.1002/asia.200900320 (2010).

29 Aggarwal, V. K. et al. Catalytic Asymmetric Synthesis of Epoxides from Aldehydes Using Sulfur Ylides with In Situ Generation of Diazocompounds. Angewandte Chemie International Edition 40, 1430-1433, doi:https://doi.org/10.1002/15213773(20010417)40:8<1430::AID-ANIE1430>3.0.CO;2-W (2001).

30 Cameron, D. R. Preparation of indoline-containing peptides as granzyme B inhibitors. US20160083422A1 (2016).

31 Benatti, L., Fariello, R., Salvati, P., Pellicciari, R. \& Caccia, C. Preparation of glycoside derivatives of 2-(3,4-dichlorobenzoyl)-cyclopropane-1-carboxylic acid as kynurenine 3-monooxygenase and glutamate release inhibitors. EP1475385A1 (2004).

32 Hendrix, J. A. et al. Preparation of heterocyclic substituted cycloalkanecarboxamides as dopamine D3 receptor ligands. WO2002066446A1 (2002).

33 Tanaka, $\mathrm{H}$. et al. Preparation of $\mathrm{N}$-acyl cyclic amine compounds as T-type calcium channel blockers. WO2020017569A1 (2020).

34 Pajouhesh, H., Pajouhesh, H. \& Kaul, R. Preparation of cyclopropylcarbonyl diarylmethyl piperazines as calcium channel blockers. WO2008043183A1 (2008).

35 Lévesque, É., Goudreau, S. R. \& Charette, A. B. Improved Zinc-Catalyzed SimmonsSmith Reaction: Access to Various 1,2,3-Trisubstituted Cyclopropanes. Organic Letters 16, 1490-1493, doi:10.1021/ol500267w (2014).

36 Minami, T. et al. Synthesis of Enantiomerically Pure 1,2,3-Trisubstituted Cyclopropane Nucleosides Using Pd-Catalyzed Substitution via Directing GroupMediated C(sp3)-H Activation as a Key Step. Organic Letters 21, 656-659, doi:10.1021/acs.orglett.8b03785 (2019). 
37 Baker, W. R. \& Martin, S. F. Preparation of cyclopropylcarbonylpeptide analogs as inhibitors of renin and retroviral protease. WO9200972A1 (1992).

38 Minato, I., Takasuka, T., Kimura, K., Sakakibara, T. \& Odaira, Y. Small Ring Compounds. I. Anodic Oxidation of 2,3-Dicarbethoxy-cyclopropanecarboxylie Acid. Bulletin of the Chemical Society of Japan 45, 965-965, doi:10.1246/bcsj.45.965 (1972).

39 Tanaka, K., Manabe, H., Irie, R. \& Oikawa, M. An Empirical Model for Stereochemical Control in the Cyclization of Cyclopropanetricarboxylic Acid Esters. Bulletin of the Chemical Society of Japan 92, 1314-1323, doi:10.1246/bcsj.20190096 (2019).

40 Boeykens, M., De Kimpe, N. \& Abbaspour Tehrani, K. Synthesis of 1-Amino-2,2dialkylcyclopropanecarboxylic Acids via Base-Induced Cyclization of .gamma.Chloro-.alpha.-imino Esters. The Journal of Organic Chemistry 59, 6973-6985, doi:10.1021/jo00102a022 (1994).

$41 \mathrm{Ni}, \mathrm{S}$. et al. A General Amino Acid Synthesis Enabled by Innate Radical CrossCoupling. Angewandte Chemie International Edition 57, 14560-14565, doi:https://doi.org/10.1002/anie.201809310 (2018).

42 Toledo-Sherman, L. M. et al. Preparation of phenylcyclopropyl carboxylic acids and similar compounds as kynurenine-3-monooxygenase inhibitors, pharmaceutical compositions containing same, and use in treating neurodegenerative disorders. WO2013151707A1 (2013).

43 Martı́n-Vilà, M. et al. Enantioselective synthetic approaches to cyclopropane and cyclobutane $\beta$-amino acids: synthesis and structural study of a conformationally constrained $\quad \beta$-dipeptide. Tetrahedron: Asymmetry 11, 3569-3584, doi:https://doi.org/10.1016/S0957-4166(00)00297-4 (2000).

44 Baldwin, J. J. et al. Acylpiperidine compounds as renin inhibitors and their preparation, pharmaceutical compositions and use in the treatment of diseases associated with aspartic protease activity. WO2007117482A2 (2007).

45 Pierik, A. J. et al. Searching for Intermediates in the Carbon Skeleton Rearrangement of 2-Methyleneglutarate to (R)-3-Methylitaconate Catalyzed by Coenzyme B12Dependent 2-Methyleneglutarate Mutase from Eubacterium barkeri. Biochemistry 44, 10541-10551, doi:10.1021/bi050049n (2005).

46 Frydman, B. et al. Cycloalkyl-substituted polyamines for cancer therapy, and methods of synthesis therefor. WO2003050072A1 (2003). 